\title{
A Psicologia da Gestalt e a Ciência Empírica Contemporânea ${ }^{1}$
}

\author{
Arno Engelmann ${ }^{2}$ \\ Universidade de São Paulo
}

\begin{abstract}
RESUMO - Wertheimer realizou um experimento que era explicado seguindo-se fatores holísticos gestálticos, e isto há mais de noventa anos. Apesar disso, estudos recentes demonstram a vivacidade desse tipo de explicação. Basicamente, ao se observar coisas do mundo, observa-se suas formas ou melhor suas Gestalten. A seguir, pode-se dividir essas Gestalten em partes. Porém cada parte será sempre parte daquela Gestalt que lhe deu inicio e não um elemento constituinte básico. A teoria da Gestalt não é exclusivamente psicológica, como o demonstraram principalmente Wertheimer, Köhler e Koffka. Iniciou-se com um experimento sobre a visão de movimentos correspondendo a estímulos estáticos, mas continuou propondo-se inclusive, de um lado, uma Gestalt física formada da corrente elétrica gestálticas dentro de um condutor ou, de outro, uma Gestalt sociológica formada de muitos seres humanos, como o dançar de pares ao som de um samba realizado por um grupo de músicos.
\end{abstract}

Palavras-chave: Psicologia da Gestalt; teoria da Gestalt; epistemologia; história da psicologia; teoria geral de sistemas.

\section{Gestalt Psychology and Empirical Contemporaneous Science}

\begin{abstract}
Although there has passed ninety years since Wertheimer's first thought to demonstrate through Gestalt explanation experimental psychology problems, the Gestalt holistic approach continues now-a-days strongly in light. In looking at the world, the Gestalten is the first happening. Then, through divisions, parts can be formed. But these parts are always parts from a formative Gestalt and not basic elements. The Gestalt approach is not exclusively psychological but rather largely empirical, as mainly Wertheimer, Köhler and Koffka have demonstrated. The beginning was a motion visual experiment in which the stimuli were static. Later Gestalt problems could be physical electric charge structure in conductors, on one side, or a sociological super-psychological Gestalt composed of dancing couples and to musicians playing a samba, on the other side.
\end{abstract}

Key words: Gestalt psychology; gestalt theory; epistemology; history of psychology; general system theory.

No outono de 1910, isto quer dizer na nossa primavera, Max Wertheimer estava de férias viajando num trem de Viena para a Renânia. No caminho olhou para um sinal ferroviário que continha duas lâmpadas. Uma lâmpada se acendia e pouco depois se apagava. Após um tempo bem pequeno, a outra lâmpada passava pelo mesmo processo. Depois, novamente a primeira lâmpada se acendia e apagava, e assim por diante. As pessoas que olhavam para o arranjo, inclusive o próprio Wertheimer, viam apenas uma luz que ia continuamente no espaço entre as duas lâmpadas, para um lado e a seguir para o outro.

Wertheimer ficou tão excitado com o que viu, que pensou na possibilidade de um experimento a respeito. Desceu do trem ao passar por Frankfurt, comprou cartolinas e um estroboscópio ${ }^{3}$ numa loja de brinquedos na cidade, alugou um quarto num hotel e começou a construir lá mesmo algumas figuras em duplicidade que deixassem a luz passar num tempo muito curto. Se a luz se acendesse e se apagasse numa figura e a seguir se acendesse e apagasse na outra, com in-

1 Parte do presente artigo é baseado numa conferência que realizei a 28-10-2000 em Brasília, na Reunião Anual da Sociedade Brasileira de Psicologia.

2 Endereço: Rua da Consolação, 3617 ap. 42,. CEP: 01416-001 - São Paulo, SP. E-mail: aengelmann@attglobal.net

3 Aparelho com clarões regulares e com espaços para a inserção de representações estáticas que permitem a "ilusão" de percepção de movimento ao se mover rapidamente. O movimento percebido é chamado de estroboscópico. tervalo entre eles de mais ou menos 60 milissegundos, enxergava-se apenas a figura indo de um lugar para outro.

Estando em Frankfurt, telefonou para o Instituto de Psicologia da Academia Comercial. Explicou seus problemas experimentais a Wolfgang Köhler, que trabalhava há pouco tempo na Academia. Köhler arranjou um espaço para Wertheimer no laboratório, arrumou um aparelho que permitisse a visão muito rápida de figuras e serviu-lhe como sujeito. Mais tarde, Köhler contou a Koffka, que também trabalhava na mesma Academia, o experimento de Wertheimer. Koffka foi o segundo sujeito e sua esposa, Mira Klein-Koffka, o terceiro. Depois Wertheimer utilizou alguns outros sujeitos sem treino de observação. O chefe do laboratório, Friedrich Schumann, ao se inteirar do experimento convidou Wertheimer a trabalhar oficialmente no laboratório (Ash, 1995; Wertheimer, 1912/1961; Wertheimer, Michael, 1970/1979.)

A percepção de um movimento diante de duas luzes rápidas e estáticas em localização diferentes, separadas por um tempo relativamente curto, fora descoberto em data bem anterior. Fora observado na primeira metade do século XIX pelo físico Plateau. $\mathrm{O}$ experimento de Plateau foi repetido com descargas elétricas por Exner em 1875. Exner foi a primeira pessoa a representar o movimento aparente como aquele no qual os estímulos não são nem lentos demais nem curtos demais. Bem mais tarde, o mesmo Exner foi professor de Wertheimer na Universidade de Praga. Houve também um grande número de pesquisadores que repetiram, e melhoraram, a percepção das ilusões de movimentos. É nessa 
época que em dezembro de 1895 os irmãos Lumière exibiram pela primeira vez aquilo que se iria configurar numa nova arte: o cinema. O cinema é realmente uma sucessão de fotografias estáticas que são apresentadas com uma rapidez tal que as pessoas que as assistem vêm, não uma série de fotografias, mas os movimentos contínuos no tempo. No entanto, a enorme pluralidade de movimentos encontrados entre uma fotografia e a seguinte não permite a perfeita realização de investigações psicológicas (Ash, 1995; Sekuler, 1996.)

A facilidade do experimento de Wertheimer é que os estímulos são extremamente simples, a ordem em que são apresentados utilizam controle de tempo (veja a Figura 1). Quando dois estímulos são apresentados com um intervalo entre eles de 200 milissegundos, os observadores vêem um percepto ${ }^{4}$, seguido de um intervalo e finalmente um segundo percepto - sucessão. Quando o intervalo entre as duas apresentações for curto, de 30 milissegundos, então os observadores vêem dois perceptos ao mesmo tempo - simultaneidade. Entretanto, quando o intervalo entre as duas apresentações for ao redor de 60 milissegundos, os observadores vêem um percepto movimentando-se da primeira localização para a segunda - movimento chamado de ótimo. O importante nesse movimento é que entre o primeiro estímulo na primeira localização e a segundo estímulo na segunda localização, há um tempo no qual não existe qualquer estímulo. Apesar disso, o sujeito ignora a correspondência entre a estimulação física e o percepto. $\mathrm{O}$ movimento, sem representante na estimulação, foi chamado de movimento fi. É muito interessante que indivíduos eram impotentes de distinguir se o fato existente da apresentação teria sido movimento real ou aparente.

Ao publicar um artigo em 1912, Wertheimer discutiu as teorias que poderiam ser utilizadas para explicar omovimento $f i$. Descartadas diversas interpretações teóricas, como por exemplo, que seriam traços, que seriam ilusões de julgamento, todas elas com falhas na explicação, apresentou a solução que achava a melhor. Tratar-se-ia de um processo total e contínuo visto como uma Gestalt ${ }^{5}$. É todavia importante, como disse Wertheimer em suas aulas de 1913, que os perceptos de objetos individuais eram Gestalten ${ }^{6}$ e o percepto do relacionamento entre os diversos objetos individuais percebidos era também uma Gestalt (Ash, 1995; Sekuler, 1996; Wertheimer, 1912/1961.)

4 "Percepto" é uma palavra de uso restrito no português do Brasil. Significa o contéudo consciente da percepção (Anjos e Ferreira, 1986/ 1999, p. 1541; Weiszflog, 1962/1998, p. 1593.) É semelhante ao uso inglês de "percept", que encontramos na obra de Köhler (1938b), por exemplo.

5 Num dicionário comum recente Gestalt “... considera os fenômenos psicológicos como totalidades organizadas, indivisíveis, articuladas, isto é, como configurações" (Houaiss, Villar e Franco, 2001, p. 1449.) Na Grande enciclopédia Larousse cultural (1995/1998, p.2703), Gestalt é a "Percepção absorvida como uma totalidade pelo indivíduo, mais do que como uma justaposição de partes".

6 "Gestalten" é o plural em alemão de "Gestalt". Em português é melhor falar em "Gestalten" do que em "Gestalts".

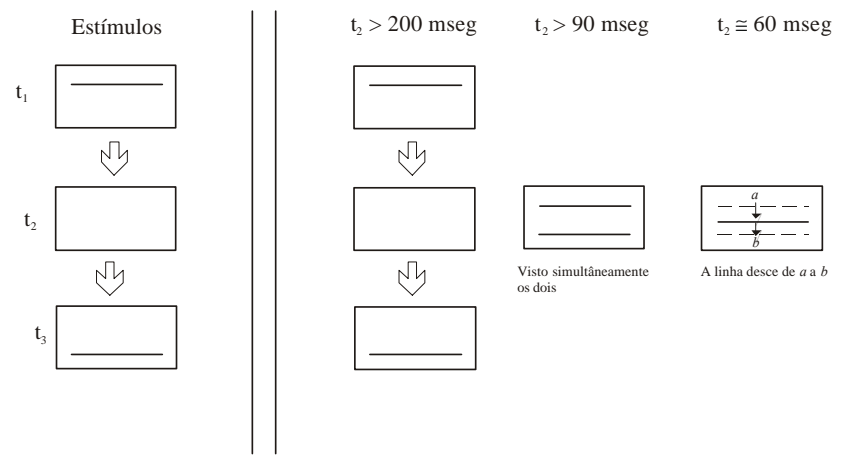

Figura 1. Percepção com três intervalos de tempo

O que se entende pela palavra "Gestalt?" O substantivo alemão "Gestalt", desde a época de Goethe, apresenta dois significados algo diferentes: (1) a forma; (2) uma entidade concreta que possui entre seus vários atributos a forma. É o segundo significado que os gestaltistas do grupo, que posteriormente vai se chamar de Berlim, utilizam. É por isso que a tradução da palavra "Gestalt" não se acha nas outras línguas e a melhor maneira encontrada pelos próprios gestaltistas ao escrever em idiomas diferentes é simplesmente mantêla (Engelmann, 1978c; Köhler, 1929/1947.)

Wertheimer disse, nos anos que se seguiram a 1912, que as Gestalten são basicamente diferentes do que se chamava na época de sensações. As Gestalten, percebidas em primeiro lugar, podem ser decompostas em partes. Mas as partes são sempre partes da Gestalt formadora. Está completamente errada a sentença, atribuída falsamente aos gestaltistas, de que "o todo é mais do que a soma dos elementos". A psicologia da Gestalt é diferente daqueles que falam em soma de elementos. Pelo contrário, a Gestalt, de início, vai ser dividida em partes. A Gestalt é anterior à existência das partes. A determinação é de cima ou descendente e não de baixo ou ascendente. Se examinarmos, por exemplo, os desenhos apresentados na Figura 2 veremos, em primeiro lugar, as Gestalten que poderíamos chamar de "linha ziguezagueante" e de "círculo." A seguir, olhando para as partes dessas Gestalten, no primeiro caso veremos pequenas retas e no segundo caso uma circunferência incompleta. É uma solução que inverte tudo o se fazia, e o que muita gente ainda faz, a descrever teoricamente os acontecimentos. Esta foi a solução de Wertheimer e a solução de seus primeiros companheirossujeitos, Koffka e Köhler, na explicação do percepto de movimento aparente e na explicação de todos os outros experimentos de psicologia (Arnheim, 1986; Ash, 1995; Köhler, 1944; Wertheimer, 1924/1938a.)

É muito importante que Wertheimer não acreditava apenas na teoria da Gestalt quanto aos acontecimentos conscientes, mas acreditava igualmente na teoria da Gestalt funcionando em sua base fisiológica. Os processos fisiológicos centrais não poderiam ser vistos como soma de elementos, mas como processos de todo. É por isso que Köhler o enxerga como um precursor do isomorfismo. Mais tarde, quando Köhler vai construir as Gestalten físicas, baseado em seu maior conhecimento da área, Wertheimer e Koffka simples- 


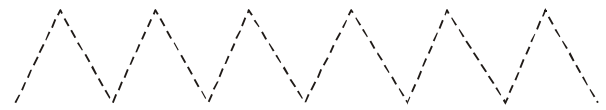

A

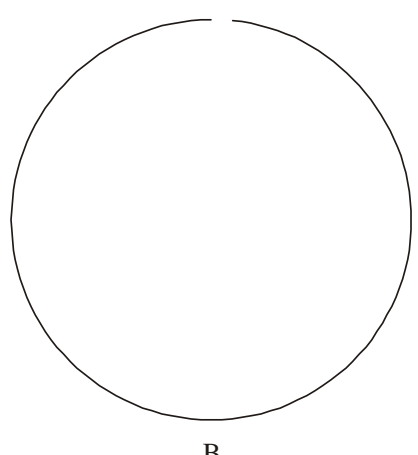

B

Figura 2. Visão de linha ziguezagueante e de círculo

mente reconhecem-no como mais um ponto da evolução da teoria comum aos três (Köhler, 1920/1938a.)

Köhler, num artigo publicado em 1913 chamado "Das sensações não percebidas e dos erros de julgamentos", rebate a teoria da maioria dos psicólogos da época e que chamou de hipótese de constância. Hipótese de constância é a correspondência um-a-um dos estímulos e das sensações. Köhler examinou longamente essa suposição e chegou às seguintes consequências: (1) ela não é auto-evidente; e (2) ela não é verificável (Ash, 1995; Köhler, 1913/1971a; Wertheimer 1912/1961.)

Em 1924, Koffka apresenta num outro artigo o que se chamava de introspecção na época. É basicamente o método analítico. Contra esse método é necessário mudar a atitude do experimentador. A atitude nova é, de início, simplesmente perceber, idêntico à maneira de qualquer pessoa que não conheça a então psicologia. É o método fenomenológico. Entretanto, qualquer acontecimento que ocorra na consciência deve ser estudado. Há psicólogos que analisam o conteúdo em elementos sensitivos, isto é, nos sons, nas cores, nos olfatos, etc. Essa método analístico não leva a problemas reais, diz Koffka. Chamei-a de observar os perceptos em fragmentos (Engelmann, no prelo; Koffka, 1924.)

\section{Elementarismo e Holismo}

A maneira epistemológica de observarinicialmente o todo é conhecida, hoje em dia, como holismo. Holismo é um termo vulgarizado por Smuts em 1926 (Goerdt, 1974.) A maioria dos psicólogos e grande parte dos outros cientistas acham que é melhor começar pelos elementos, aos quais se chega dividindo o todo. Essa maneira é conhecida como elementarismo.

O holismo não deve ser compreendido, como o quis Bunge (1977), no qual o enorme Universo seria necessariamente um todo orgânico e a única maneira de estudá-lo é por meio da intuição. Experimentos não teriam lugar nesse holismo de Bunge. Seria uma volta a especulações semimísticas. Ainda que se possa também incluir esses tais semimísticos na mesma classificação, os gestaltistas são, em primeiro lugar, cientistas empíricos. A seguir enxergam sua abordagem ao problema, que é holista e não elementarista (Ash, 1995.)

Já Aristóteles escrevia, no longínquo século IV A.C., que "O todo é, com efeito, necessariamente anterior à parte, ..." O importante sempre é a "...forma total..." e não os "...elementos que nunca surgem separados do ser ao qual pertencem." Afirmava que o todo deve ser considerado algo de diferente da simples reunião dos elementos. Dava vários exemplos. Quando se quer estudar uma casa, o importante é mesmo a casa e não os elementos de tijolos, de pedaços de madeira que nunca são separados do ser ao qual pertencem. Ou, com a morte e a destruição do corpo inteiro não resta o que se entenderia por mãos ou por pés individuais. As mãos e os pés são partes do corpo. Quando o corpo deixa de existir, as antigas partes perdem a sua função. Ou, os seres humanos são unidos em famílias, as famílias em aldeias, as aldeias em cidades no caso da Grécia Antiga. Essa união é natural e necessária. Uma cidade formava uma comunidade que era algo de diferente do que a justaposição de aldeias (Aristóteles, 1953, 1956, 1962; Ross, 1923/1949.)

Essa abordagem aristotélica holística foi negada no século XVII, quando Galileu e Descartes deram os primeiros passos na explicação da natureza. Descobriram que a explicação da função das partes era extremamente importante. Entretanto, conhecer a função dessas partes seria, de acordo com eles, suficiente. Não se trata mais das partes do todo, mas dos elementos que se apresentam como fundamentais (Bertalanffy, 1975.) É a base da doutrina do reducionismo ${ }^{9}$.

\section{Conteúdo Psicológico Consciente Humano e Alargamento deste Conteúdo}

\section{Conteúdo psicológico consciente humano}

Os primeiros estudos da escola da Gestalt foram realizados na organização da parte perceptiva consciente. Em 1914, Wertheimer discutindo no Congresso da Sociedade de Psicologia Experimental com Benussi, um membro de outra linha gestáltica, achou que, diante dos principais fatores perceptivos, havia uma lei que os subordina e que denominou de pregnância. Por lei da pregnância entende-se uma organização psicológica que pode sempre ser tão boa quan-

7 Tradução francesa por J. Tricot de Aristóteles (1962) da Política, I, 2, 1253a, 20, retraduzida por mim.

8 Tradução francesa por P. Louis de Aristóteles (1956) da Partes dos animais, $I, \mathrm{~V}, 645 \mathrm{a}$, retraduzida por mim.

9 Reducionismo é a doutrina que, acreditando-se num Universo único, encara a redução total dos acontecimentos complexos nos acontecimentos mais simples e formadores, ainda que seja atualmente uma redução puramente teórica. Por exemplo, a redução iria das sociedades humanas aos indivíduos humanos, iria das células às moléculas, etc. 
to as condições o permitirem. O termo "bom" permanece não definido. Abarca propriedades como regularidade, simetria, simplicidade e outros. Sejam três dos fatores que Wertheimer cita: o fator de proximidade (veja a Figura 3), o fator de semelhança (veja a Figura 4) e o fator de fechamento (veja a Figura 5). Na Figura 3, no desenho à esquerda, a lei da pregnância organiza os quadrados em quatro colunas baseadas na proximidade maior entre eles; no desenho à direita, a proximidade maior é entre os quadrados que vão constituir três barras horizontais. Na Figura 4 o fator de semelhança organiza os quadrados em duas colunas: duas brancas e duas pretas. Na Figura 5, os pontos se organizam em duas áreas fechadas. Wertheimer esperou até 1923 para publicar um artigo sobre o assunto (Ash, 1995; Koffka, 1935/ 1975; Wertheimer, 1923/1938b.)

\section{Não apenas experiência, mas também ação}

Num artigo de crítica a Benussi, Koffka alarga o que se pode entender por Gestalt. Koffka pensa em Gestalten não apenas na experiência, mas também nas ações dos indivíduos. Cantar, escrever, desenhar, andar são Gestalten tanto quanto a consciência de ouvir ou de olhar. "O ato motor é um processo-de-todo organizado; os muitos movimentos individuais podem ser compreendidos somente como partes do processo que os abraça ...."10 (Ash, 1995; Koffka, 1915/1938.)

Os correlatos fisiológicos da percepção e da ação, não são excitações individuais mas eventos unificados. São, como Wertheimer o acentuou, Gestalten.

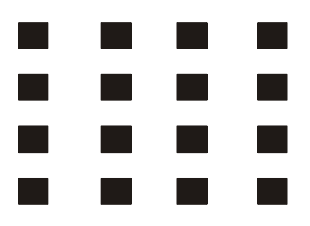

(a)

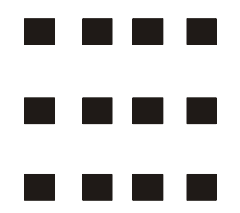

(b)
Figura 3. Dois fatores de proximidade

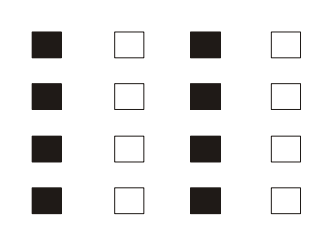

Figura 4. Fator de semelhança

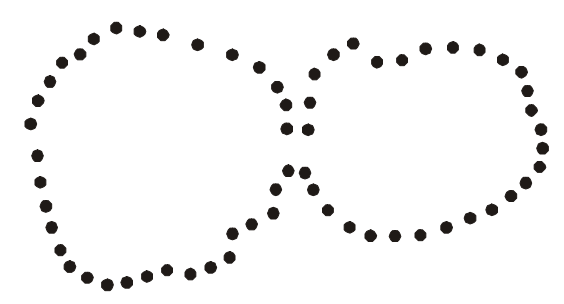

Figura 5. Fator de fechamento
Não apenas seres humanos, mas também outros animais.

Em dezembro de 1913, Köhler consegue o posto de Diretor da estação de pesquisa da Fundação da Academia Prussiana, em Tenerife nas ilhas Canárias. A colônia alemã dos Camarões ${ }^{11}$ tinha um clima demasiado quente para os cientistas. De outro lado, os chimpanzés que iriam ser estudados não se aclimatavam na Alemanha. A Fundação então foi localizada numa ilha espanhola perto do Marrocos. Köhler aceitou o posto, principalmente para estudar a inteligência de chimpanzés. Os estudos estavam, de um certo modo, completos em junho de 1914. Pouco depois começou a guerra. Köhler foi chamado como reservista em julho do mesmo ano. Entretanto, por estar em idade militar, possuía dificuldade de atravessar uma área cheia de navios aliados. Permaneceu em Tenerife até 1920, na Espanha neutra. Apesar de doenças, nele e em sua família, aproveitou sua estada para pesquisar e escrever muito com relação aos animais e muito com relação às Gestalten físicas.

Thorndike havia publicado nos Estados Unidos, em 1898, um trabalho realizado principalmente com gatos e cães, no qual demonstrava a longa aprendizagem para abrir uma porta, atrás da qual se encontravam alimentos. A tradução teórica dessa aprendizagem era a união associativa entre impressões sensoriais e impulsos motores. A investigação de Thorndike representava o contrário do que estava sendo esperado por gestaltistas e por evolucionistas como Hobhouse e Yerkes.

O espírito do experimento de Thorndike foi repetido por Köhler. O objetivo da investigação era sempre a aquisição de um alimento. $\mathrm{O}$ alimento, durante pouco tempo, estava perto do sujeito experimental. A seguir, era colocado num ponto visível, mas que o sujeito não podia alcançar continuando o caminho antigo e reto. Um caminho novo, que começava com o sujeito afastando-se do alimento, era a solução. Como sujeitos, além de chimpanzés, utilizou galinhas, um cão e sua própria filha com três meses de idade. Duas formas de comportamento foram demonstradas (veja a Figura 6.) De um lado, a realização genuína, que foi o caminho eficaz utilizado pelo cão, pelos chimpanzés e pela criança. De outro, a imitação por acaso, que foi o caminho em ziguezague usado inicialmente pelas galinhas. Em poucos casos e após um tempo em ziguezague, algumas galinhas mudavam de forma de comportamento e corriam de acordo com a realização genuína.

Entretanto, os experimentos mais interessantes foram aqueles nos quais os chimpanzés se encontravam numa situação no qual o alimento, a banana, era posto fora do seu alcance. Procuravam diversas soluções e repentinamente o desfecho chegava. É o "Einsicht" ou sua tradução inglesa

10 Tradução minha de um trecho traduzido para o inglês na p. 377 de Koffka (1938.)

11 Os Camarões foram colônia alemã de 1884 até 1916. A seguir tiveram o território dividido entre a França e a Grã Bretanha. Atualmente é uma república independente. 
a. Realização genuína

b. Imitação por acaso

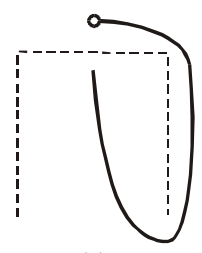

(a)

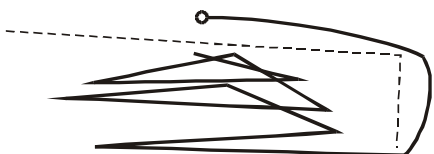

(b)
Figura 6. Duas formas de comportamento diante de um problema

insight. Essa palavra inglesa foi importada por diversas línguas, inclusive por nosso português. O critério de insight é o aparecimento de uma solução completa com relação à estrutura do campo, como disse Köhler. O chimpanzé, após o insight, realiza genuinamente o caminho que leva à solução do problema, inclusive utilizando utensílios para a nova função ou até inventando-os (Ash, 1995; Köhler, 1917/1927.)

O insight era uma solução momentânea. Os psicólogos da Gestalt não são nativistas. Entretanto, a solução de um problema requisita exclusivamente uma reorganização do campo para o sujeito. Procurar fatores que ocorreram no passado não interessa a esses psicólogos.

\section{Não apenas teoria psicológica da Gestalt, mas teoria gestáltica ampla sobre o Universo}

É verdade que os germes da teoria explícita de Köhler já se encontrava nas idéias iniciais de Wertheimer. Köhler trabalhou de 1915 a 1917 no livro "Gestalten fisicas em repouso e em estado estacionário". Mandou-o para a Alemanha com a recomendação que fosse publicado, isto em 1917. Sabia que a maneira de tratar de assuntos físicos e matemáticos poderia ser considerada muito elementar. Afinal, apesar de ter seguido muitas matérias de física, era apenas um psicólogo. Recebeu inúmeras críticas, mas a opinião favorável de Albert Einstein permitiu que fosse editado sob a forma que tinha sido apresentado (Ash, 1995.)

No livro Köhler diferencia entre e-somas, formado pela soma genuína dos elementos, e sistemas fisicos, nos quais não há partes do sistema que mudem sem alterar o sistema como um todo. Um exemplo de sistema fisico seria o condutor elétrico isolado. A carga elétrica no condutor não depende em nada de pequenas cargas elétricas de trechos desse mesmo condutor. Pode-se falar em física apenas na eletricidade do condutor, não nas suas subdivisões. $O$ condutor só pode ser visto como um sistema físico.

Um sistema físico pode mostrar-se (1) em repouso, (2) num processo estacionário no qual há uma mudança constante mas cujo resultado é continuar com as propriedades em repouso, (3) num processo quase-estacionário no qual a mudança gradativa no tempo é tão lenta que o resultado será quase idêntico ao processo estacionário, (4) num processo estacionário periódico no qual há uma repetição contínua tal que o novo resultado mantenha as mesmas propriedades de repouso e, finalmente, (5) num processo dinâmico resultando numa mudança.

Köhler acha que as distribuições físicas estacionárias apresentam a mesma tendência que Wertheimer denominou de lei da pregnância. Por exemplo, ao se soprar com um canudo para constituir uma bolha de sabão, essa bolha, ao se libertar, apresentará uma forma esférica, aquela que tem menor superfície para um máximo de volume (Köhler, 1920/ 1938a.)

Percebe-se como no espaço de poucos anos a teoria psicológica da Gestalt vai se transformando numa teoria ampla do Universo. A física também pode ser gestáltica; mas seria elementarista enquanto lida com e-somas. Seria isto que Köhler pensava?

"Pode-se ignorar, como assunto de determinação específica, se houve interação entre um processo e seu ambiente, além do tamanho de sua área. O primeiro passo em qualquer experimento físico é determinar se houve esse fato." ${ }^{12}$ A hipótese da interação universal atrai consigo uma visão da natureza completamente errônea. Não se pode aceitá-la. Por conseqüência, deve-se supor elementos independentes.

\section{O Isomorfismo Psiconeural}

Como os acima citados sistemas físicos se ajustam ao sistema nervoso? Pelo que se sabe, o sistema nervoso é formado por uma série enorme de neurônios que se comunicam uns com os outros segregando substâncias químicas nas sinapses, que irão, por sua vez e nas próprias sinapses, excitar outros neurônios. De acordo com Köhler, essas substâncias químicas se juntarão formando um grande conjunto fora dos neurônios. Esse conjunto é o lugar de sistemas físicos elétricos tridimensionais. As excitações provocadas causariam processos estacionários ou quase-estacionários (Köhler, 1920/1938a, 1938b; Köhler \& Wallach, 1944.)

Num verso do seu poema "Epyrrhema", Goethe havia dito: "O que está dentro, aquilo está fora." ${ }^{13}$ Köhler o coloca na abertura do capítulo sobre isomorfismo psiconeural. Köhler acredita no isomorfismo, isto quer dizer, que as Gestalten fenomenológicas da consciência teriam a mesma forma ou seguiriam a mesma matemática topológica que as estruturas físicas. Topológicas são relações do tipo "dentro" ou "fora", "entre", "em contato com", “à distância de". É importante que o isomorfismo psiconeural se estabelece apenas para levar em conta a parte do sistema nervoso que é capaz de apresentar uma face fenomenológica. Evidentemente, há uma grande parte para a qual não haveria dupla representação.

A hipótese é monista: as duas faces seriam maneiras de se olhar a mesma coisa. As duas faces não seriam apenas análogas, mas seriam paralelas, nas palavras do próprio Köhler, ainda que paralelo não seja de maneira nenhuma idêntico. Além disso, a hipótese do isomorfismo psiconeural

12 Tradução minha do resumo de Köhler (1938a, p. 30.)

13 Tradução minha da citação de Goethe por Köhler (1938a, p. 33.) 
é realista. O Universo é uma realidade só (Engelmann, 1978c; Koffka, 1935/1975; Köhler, 1920/1938a, 1938b, 1929/1947; Köhler \& Wallach, 1944; Lewin, 1936.)

\section{Força da Gestalt}

Köhler (1920/1938a) definiu dentro dos sistemas físicos a força da Gestalt como o grau de interdependência de suas partes. Uma Gestalt éfraca quando a energia de seu processo é pequena. Uma Gestalt é forte quando a energia do processo aumenta. Dentro dos vários sistemas físicos, há os constituídos por processos nervosos centrais de animais superiores. Através do isomorfismo psiconeural, os mesmos processos se aplicam aos processos neurais e aos fenomenológicos. Koffka (1935/1975) retomou essa diferenciação, devida a Köhler, e aplicou-a à realidade de grupos sociais.

Podemos citar como exemplo, um ser humano sentado ante sua escrevaninha, em cima da qual há uma borracha e um livro. Podemos dizer que a borracha constitui uma Gestalt forte e o mesmo pode-se dizer com relação ao livro. A superfície da mesa com os dois objetos, borracha e livro, constitui também uma Gestalt. Entretanto, será uma Gestalt bem mais fraca do que as duas Gestalten anteriores, a borracha e o livro. Através do isomorfismo, na medida em que o ser humano olha para a mesa, os perceptos "borracha", "livro" e "alto da mesa contendo a borracha e o livro" são também Gestalten, com a seguinte diferença entre elas: "borracha" e "livro" apresentam mais força do que "alto da mesa contendo a borracha e o livro". Outro exemplo, seria o de duas pessoas carregando um sofá. As duas pessoas seriam cada um uma Gestalt, o sofá também. Além disso, as duas pessoas carregando o sofá seria uma terceira Gestalt, ainda que mais fraca do que as três Gestalten anteriores.

Para mim, ao se falar nos diversos graus de força da Gestalt, seria bem melhor utilizar um contínuo. Nesse contínuo seria possível colocar uma Gestalt muito forte, uma Gestalt medianamente forte, uma Gestalt mais ou menos fraca, uma Gestalt bem fraca, e assim por diante.

No contínuo de forças da Gestalt, o que denominaríamos de força de quase nula? Por exemplo, a Gestalt formada pelos perceptos de uma borracha na mesa e mais a lua, no momento em que é visível através da janela. Ainda que possua alguma força, praticamente o valor seria tão pequeno que seria melhor nulificá-la para efeitos práticos. Como disse Köhler numa nota na página 31 da redução do livro Gestalten fisicas por Ellis, o grau dos limites da Gestalt nunca é abrupto (Köhler, 1920/1938a.)

\section{As Escolas Gestálticas}

Como vimos, a abordagem radical de Wertheimer, Koffka e Köhler a fatos psicológicos é conhecida atualmente como gestaltista. Antigamente seus representantes constituíam a chamada escola de Berlim. Berlim, como se sabe, era durante a república de Weimar ${ }^{14}$ sede do Instituto de Psicologia chefiado por Köhler. Nele trabalhou Wertheimer até 1929, antes de mudar-se para o laboratório de Frankfurt. Koffka, era professor em Giessen, mas vinha continuamente a Berlim. Em 1927, foi o primeiro dos três psicólogos a se mudar para os Estados Unidos por ter conseguido uma cadeira no Smith College, perto de Boston (Ash, 1995; Boring, 1929/1950; Michael Wertheimer, 1979).

A escola de Berlim não era a única escola gestaltista na época. A primeira é, de certa forma, a precursora de todas as outras. É conhecida como escola da qualidade gestáltica ou, durante algum tempo, escola de Graz. Há ainda uma outra que deve ser citada. É a escola da totalidade ou segunda escola de Leipzig ${ }^{15}$.

\section{Escola da "Gestaltqualität" ou qualidade gestáltica}

Antes do experimento de Wertheimer com que iniciamos o artigo, houve uma inquietação que surgiu na psicologia já em 1890, quando Christian von Ehrenfels publicou um artigo famoso, Über Gestaltqualitäten, ou em português Das qualidades gestálticas. Para Ehrenfels, "Gestalt" não seria apenas um conceito estético de beleza, como o era na época, mas também um conceito psicológico. Todavia, em vez de utilizar o termo antigo e substantivo "Gestalt", Ehrenfels vai exprimir-se através do substantivo qualificador "Gestaltqualität" ou "qualidade gestáltica." As experiências seriam em sua base abstrata formadas por sensações e sentimentos elementares, como o requeria Wundt ${ }^{16}$. As sensações vão se unificar em qualidades gestálticas, sendo cada qualidade gestáltica, não a soma dos elementos que a compõe, mas uma categoria própria que seria mais do que a adição. Assim, por exemplo, uma determinada melodia poderia ser tocada pelo piano, pelo violino ou pelo violão. A melodia é a mesma, apesar de possuir nos três instrumentos diferentes timbres característicos. Ainda mais, uma mesma melodia poderia ser tocada no piano com o tom de dó maior, de mi maior ou de fá maior. Ela será sempre a mesma melodia ainda que constituída por notas diferentes, isto é, formada por elementos diferentes. Mais tarde, Köhler (1920/1938a) proporia dois critérios que, do seu ponto de vista, caracterizam o pensamento de Ehrenfels: o critério de supra-somatividade, isto é, que as qualidades gestálticas não seriam constituídas pelas sensações elementares, e o critério de transponibilidade, isto é, as relações das qualidades gestálticas não mudariam apesar de trocas nas sensações. É importante lem-

14 Na Alemanha, chama-se de república de Weimar o período limitado pelo fim da Primeira Grande Guerra e 1933, estabelecimento da ditadura de Hitler. Weimar é o nome da cidade alemã onde se escreveu a primeira constituição republicana.

15 A primeira escola de Leipzig é constituída por Wundt e seus assistentes.

16 Wundt era, na época, o mais importante psicólogo experimental. Nos anos entre 1858 e 1862 publicou um livro em que conceitua uma "psicologia experimental" que necessariamente deve iniciar-se pela introspecção e que possui dois auxiliares: a história e a experimentação. Em 1879, recebe autorização para fundar o primeiro laboratório de psicologia do mundo na Universidade de Leipzig (Boring, 1929/ 1950; W. Bringmann, N. Bringmann e Ungerer, 1980.) 
brar que Max Wertheimer foi discípulo de Ehrenfels quando aluno em Praga, isto no período que começou em 1898.

Ehrenfels recebeu o título de doutor na Universidade de Graz, na Aústria, sob a responsabilidade de Meinong em 1885. Era seis anos mais jovem que seu orientador. Entre os dois nasceu uma forte amizade. Em 1890, Ehrenfels propôs ao amigo sua teoria: além das sensações, haveria qualidades gestálticas. Meinong concordou com a diferenciação feita por Ehrenfels, porém discordou com a terminologia. A palavra "Gestalt" poderia envolver uma realidade extrapsicológica. Na linguagem de Meinong tratar-se-ia de um processo com dois estágios: o primeiro daria origem a "conteúdos fundadores"; o segundo, a "conteúdos fundados". Meinong e seus discípulos são conhecidos como membros da escola de Graz ou, às vezes, como psicólogos austríacos. Seus dois assistentes, Witasek e Benussi, foram as primeiras pessoas a realizarem experimentos gestálticos (Ash, 1995; Boring, 1929/1950; Heider, 1970; Herrmann, 1974b; Metzger, 1974a, 1974b, 1974c; Strube, 1974; Wundt, 1896/1905.)

Benussi, natural de Trieste, foi até o fim da Primeira Guerra Mundial cidadão da Aústria-Hungria. Com os resultados da guerra passou a ser cidadão italiano. Benussi queria profundamente a mudança de sua nacionalidade, pois que desde sua infância o sentimento político dentro de sua casa era pró-italiano e anti-austríaco. Na Itália foi reger a cadeira de psicologia da Universidade de Pádua até seu falecimento em 1927. Ainda que seus experimentos fossem muito bem considerados pelos componentes da escola de Berlim, Benussi manteve até o fim de sua vida confiança na representação de Meinong. Musatti, um discípulo e mais tarde substituto de Benussi em Pádua, no início recebeu a formação teórica do mestre. A seguir da morte de Benussi, abriuse às críticas dos berlinenses, porém jamais aceitou-as completamente. Nunca deixou de ressaltar na teoria o efeito da experiência passada na percepção. Entretanto, foi através de seus discípulos principais, Metelli e Kanisza, que os psicólogos gestaltistas italianos mudaram sua orientação, desta vez aceitando a crítica à explicação de Meinong feito pela escola de Berlim (Heider, 1970; Verstegen, 2000.)

\section{A "Ganzheitspsychologie" ou psicologia da totalidade}

A Ganzheitspsychologie ou psicologia da totalidade é outra escola conhecida como gestáltica. Foi iniciada por Felix Krueger, sucessor de Wundt na psicologia da Universidade de Leipzig. Ao contrário da teoria de Wundt, punha como prévio a totalidade. Totalidade para Krueger e seus discípulos era uma outra maneira de qualificar o que tem sido estabelecido como Gestalt. Contudo, Krueger achava que a grande diferença que tinha com relação à psicologia gestáltica é colocar como situação básica a afetividade. A afetividade é destruída através da análise, quando psicólogos de natureza wundtiana realizavam a observação (Herrmann, 1974a, 1974b; Sander, 1930.)

Além disso, houve um interesse grande na evolução individual das Gestalten. Sander, assistente de Krueger, apresentou um método para pesquisar as diversas etapas por que passaria um ser humano adulto na formação de suas Gestalten normais. As durações extremamente pequenas foram conseguidas através de um taquistoscópio ${ }^{17}$. Nesse caso, os indivíduos percebem Gestalten nas quais preponderam fatores de organização internos, isto é, que existem por efeito da própria organização. Exemplos seria a regularidade maior, divisão em figura e fundo. Ao contrário, fatores de organização externos seriam aqueles que apresentam maior influência da estimulação e que se mostram em perceptos de duração comum. O produto será sempre uma combinação dos fatores externos e internos.

Segundo estudos empíricos de um assistente de Sander, Undeutsch, as fases por que passam as Gestalten, ou melhor as Pré-Gestalten transformando-se com durações maiores em Gestalten, seriam quatro: primeiro, a percepção difusa e indiferenciada; a seguir, uma organização, como a figura e o fundo; posteriormente, uma fase em que se percebe contornos e conteúdos internos; e, finalmente, a Gestalt normal. A Pré-Gestalt inicial seria um todo quase exclusivamente de fatores internos. Com o aumento da duração, aumenta também a ação de fatores externos. Sander acha que as quatro fases perceptíveis, que inúmeros experimentadores alemães apresentaram, seriam as fases normais da percepção de uma Gestalt. Há inclusive um estudo de Sommer no qual a seqüência normal foi invertida, isto é, os sujeitos viam primeiro a Gestalt normal; depois a apresentação visual da figura ia sendo apresentada com durações cada vez menores. Apesar disso, encontrou-se as mesmas quatro fases (Flavell \& Draguns, 1957; Sander, 1928/1967, 1930.)

O procedimento foi denominado por Sander de Aktualgenese é traduzido para o inglês pela tradutora Langer como realização genética. Heinz Werner, um psicólogo alemão do mesmo grupo, que mais tarde emigrou para os Estados Unidos por causa do nazismo, chamou o método de microgenética. Com esse nome estão sendo feitos experimentos até hoje em dia (Flavell \& Draguns, 1957; Sander, 1930; Werner, 1956.)

\section{Mudança dos Fundadores da Psicologia da Gestalt para os Estados Unidos}

Nos primeiros anos do governo nazista na Alemanha, dois dos fundadores da psicologia da Gestalt, Wertheimer e Köhler, o primeiro por ser judeu e o outro por ter-se oficialmente posicionado contra o nazismo, deixaram a Alemanha. Receberam postos em universidades americanas: Wertheimer na New School for Social Research em New York; Köhler no Swarthmore College perto de Filadélfia. É interessante que com sua chegada ao país em que Koffka trabalhava desde 1927, os três membros da antiga escola de Berlim estavam de novo próximos entre eles.

17 Taquistoscópio é um instrumento em que os estímulos visuais são apresentados em durações controladas. 
$\mathrm{Na}$ época, a maioria dos americanos era behaviorista. John Watson, iniciador do movimento através de um artigo apresentado em 1913, "A visão da psicologia por um behaviorista", achava que a psicologia deveria seguir o mesmo procedimento utilizado pelos fisiólogos e pelos outros cientistas naturais. Deveria estudar os organismos humanos e nãohumanos fora dos observadores. Os gestaltistas lutavam por uma nova maneira compreender os organismos, partindo inicialmente do todo e vendo como esse todo se relaciona com suas diversas partes. Essas duas caracterizações dos dois tipos de psicologia apresentam algum ponto de conflito? Do meu ponto de vista e quanto ao ponto básico da escola de psicologia, não (Koffka, 1935/1975; Köhler, 1929/1947; Watson, 1913/1961.)

Porém, se formos para outros aspectos das teorizações, Watson (1919/1929), Hull (1951), Skinner (1953) e Osgood (1953) apresentam-se com influências elementaristas. Os gestaltistas, pelo contrário, acreditavam que a posição inicial dos psicólogos era totalmente diferente. Tolman (1932), apesar de sempre se qualificar de behaviorista, introduziu inúmeras concepções gestaltistas em sua teoria.

Em 1941, faleceu Koffka. Em 1935 havia publicado um livro básico que contém a parte teórica e as principais pesquisas da psicologia da Gestalt. Foi traduzido para diversas línguas entre as quais o português (Koffka, 1935/1975.)

Utilizando uma abordagem de teoria do campo psicológica, Koffka apresenta como base a interação entre organismo e meio. O meio, sem o organismo, é geográfico. Esse meio geográfico determina em cada organismo um meio comportamental. Parte desse meio comportamental dá origem à experiência direta ou, em outra linguagem, consciência. Essa experiência direta e a sua base fisiológica apresentam-se como topologicamente correspondentes. É o isomorfismo psiconeural. A experiência direta pode ter como um de seus objetos o Ego, tudo que está dentro da pele. O resto será o objeto, aquilo que está fora da pele. A organização será então bipolar: Ego-objeto. Dentro dessa concepção teórica, Koffka cita uma série de experimentos (Koffka, 1935/1975.)

Dois anos depois da morte de Koffka, faleceu Wertheimer. Publicou em seus últimos anos um livro sobre o pensamento e solução de problemas. Nesse livro volta a preocupações que mantinha na Alemanha. Dizia que a falta de clareza leva o indivíduo a procurar várias tentativas até achar a solução (Wertheimer, 1945.)

Köhler, ao contrário de seus companheiros, viveu até 1967. Continuou trabalhando na mesma universidade e, depois de aposentado, pesquisou junto ao Dartmouth College, na Nova Inglaterra. Entre outros experimentos, procurou demonstrar em organismos o isomorfismo psiconeural.

Dada a semelhança entre a organização fenomenológica ou "dentro" e a organização física do cérebro ou "fora", e dada muito maior conhecimento das Gestalten imediatas do que das mediatas, é muito melhor estudarmos fatos conscientes do que fatos físicos que lhe são psiconeuralmente isomórficos, disse Köhler. A teoria isomórfica, entretanto, vai de encontro à concepção comum, pelo menos durante a época da vida de Köhler.
Diversos estudos tentaram evidenciar o errôneo de correntes diretas no cérebro. Forgus, no entanto, encontrou nessas pesquisas sempre explicações falhas. Na mesma época, Köhler achou muito importante experimentos que mostrassem o contrário: a verdade das idéias da teoria gestáltica do isomorfismo psiconeural. Praticamente, tentou comprovar a existência de correntes corticais. Numa série de experimentos, nas quais o próprio Köhler foi o sujeito, demonstrou-se que a visão de um objeto que se movia lentamente passando pela fóvea dava origem a correntes diretas. Mas passando pelo crânio humano, os resultados são correntes muito fracas. Os experimentos foram repetidos com um gato, no qual os eletrodos foram introduzidos no cérebro. Nesse caso as correntes foram bem mais fortes (Forgus, 1966/1971; Henle, 1984; Köhler, 1920/1938a, 1938b, 1969, 1957/1971b)

\section{A Teoria Geral de Sistemas e a Teoria da Gestalt}

Em fins da década de 1920, o biólogo Ludwig von Bertalanffy julgou que as duas principais explicações embriológicas, então existentes, estavam erradas. A primeira partia dos elementos e explicava todas as formações em termos mecanicistas. O desenvolvimento de um embrião seria explicado desta maneira. A segunda propunha uma explicação vitalista que se superpunha à explicação elementar. De acordo com Driesch, o ser vivo mantinha-se graças à sua enteléquia ${ }^{18}$, à sua capacidade de constituir-se tendo em vista o seu fim. De acordo com von Bertalanffy, a nova explicação era apenas uma maneira de colocar uma pergunta importantíssima na explicação mecanicista. Entretanto, não procurava resolvê-la. A solução do problema que Bertalanffy encontrou era gestáltica. A Gestalt, apesar de nascer na psicologia, era demonstrada na biologia e também na física. Era uma maneira nova de abordar o problema (Bertalanffy, 1933, 1977; Köhler, 1920/1938a, 1927/1971c.)

Os seres vivos apresentam-se numa série hierárquica. Para Lloyd Morgan, em um nível há uma porção do Universo com uma maneira de organização que surgiu como emergência de um outro nível inferior. Os vários sistemas se organizam em níveis e esses níveis são cada vez maiores à medida que se pode subir. A ciência empírica deve reconhecer tanto a abordagem gestáltica quanto a dos emergentistas (Bertalanffy, 1933, 1975; Goudge, 1967; Jantsch, 1980.)

Von Bertalanffy achou importante reunir físicos, químicos, biólogos, psicólogos, sociólogos, matemáticos e outros ao fundar a Sociedade de Pesquisa Geral de Sistemas. Isso ocorreu em 1954. O conceito fundamental é o de sistema. Um sistema, pelo menos de acordo com von Bertalanffy como vimos acima, seria uma Gestalt. Entretanto, há cientistas empíricos para os quais os quais os sistemas seriam construídos a partir de elementos e não de Gestalten (Bertalanffy, 1977; 1975.)

18 Enteléquia é um termo grego criado por Aristóteles. Significa a forma que determina a atualização de uma potência. Foi retomado por Driesch. 
Há diferentes classificações por sistematistas baseadas em sua visão do mundo. Por exemplo, em 1942 o químico Needham achava que o Universo apresentava os seguintes níveis, partindo do menor: organização subatômica $\rightarrow$ átomo $\rightarrow$ molécula $\rightarrow$ partícula coloidal $\rightarrow$ célula viva $\rightarrow$ órgão $\rightarrow$ organismo $\rightarrow$ entidade psicológica $\rightarrow$ entidade sociológica. O biólogo Bertalanffy, em 1967, julgava que a passagem das organizações menores até as maiores consiste em: partículas elementares $\rightarrow$ átomos $\rightarrow$ moléculas $\rightarrow$ células $\rightarrow$ organismos $\rightarrow$ organizações supra-individuais. O psicólogo James G. Miller, em 1978, acha que os níveis compreendiam: partículas $\rightarrow$ átomos $\rightarrow$ moléculas $\rightarrow$ cristais ou organelas. A seguir haveria uma repartição. Os níveis superiores minerais apresentavam o seguinte esquema: sistemas ecológicos $\rightarrow$ planetas $\rightarrow$ sistemas solares $\rightarrow$ galáxias $\rightarrow$ outros sistemas superiores; os níveis superiores vivos incluíam células $\rightarrow$ órgãos $\rightarrow$ organismos $\rightarrow$ grupos $\rightarrow$ organizações $\rightarrow$ sociedades $\rightarrow$ sistemas supranacionais (Bertalanffy, 1977; Miller, 1978; Needham, 1942.)

Há pontos em que discordo de alguns representantes da teoria geral de sistemas. Por exemplo, ainda que a classificação hierárquica em níveis seja, de um modo geral, válida, não aceito os isomorfismos entre os vários níveis, como os de von Bertalanffy ou os de Miller. Esses isomorfismos são distintos do isomorfismo psiconeural de Köhler. São identidades formais entre vários níveis. As semelhanças entre os diferentes níveis não me parecem, até o momento, convincentes (Bertalanffy, 1977; Miller, 1978.)

Em 1959, Köhler fazia parte dos intelectuais que iam discutir o problema das "Dimensões da mente". Na parte final de sua comunicação, Köhler levanta o problema das pessoas que acham que a solução do problema da mente residia em “... uma emergência incompreensível”"19. Para ele a conclusão melhor para a questão consciência-cérebro consistia no isomorfismo psiconeural, isto é, na semelhança das “... características estruturais dos processos cerebrais e dos eventos fenomenológicos relacionados ...."20.

Scheerer achava que para Köhler uma solução horizontal, na qual as diversas emergências de camadas compreendiam cada uma um aumento de complexidade, era contraproducente. Ao contrário, Köhler pensava na existência de um limite vertical entre as distribuições dinâmicas — pelo menos nos seres vivos - e as funções de tipo máquina (Köhler, 1960/1978; Scheerer, 1994.)

A base da teoria das emergências consiste na existência de níveis em que cada sistema reconstrói o nível imediatamente inferior, já que o novo sistema apresenta melhor eficiência. Entretanto, apesar dos vários sistemas se originarem de baixo para cima, cada novo sistema é uma Gestalt e, enquanto Gestalt, suas leis de organização são de cima para baixo. Um desses níveis é o organismo. Uma pequena parte desse organismo mostra-se como consciente, isto é, o próprio organismo conhece essa parte. Qual a maneira para ex-

19 Trecho do artigo de Köhler (1978, p. 145.)

20 Outro trecho do mesmo artigo de Köhler (1978, p. 145.)

plicar o conhecimento desta parte, quer dizer, que relação existe entre a consciência e a base desta consciência? Não sei. A relação isomórfica entre o psíquico e o neural é uma hipótese muito boa.

Muitos teóricos acreditam ao mesmo tempo na abordagem gestáltica e na abordagem das emergências, e sou um deles. Dou um exemplo de uma brasileira que pesquisou danças de salão (veja a Figura 7). Suponhamos que quatro pares, isto é, um cavalheiro e uma dama, estão dançando um samba. Uma orquestra de três pessoas está tocando a música. Em cada par, a dama é uma pessoa e o cavalheiro é outra. Aceitando-se a classificação em níveis, cada pessoa é um organismo. Entretanto, o que interessava a investigadora é o movimento do par que executa a dança e não o movimento de cada organismo. Este movimento é grupal. Há quatro grupos e esses grupos dançam a música tocada por três músicos. De outro lado os três músicos tocam em conjunto. São portanto quatro pares dançando e mais o grupo dos três músicos. Grupo é um conjunto de pessoas em contato perceptível. No presente caso teremos um grupo de organismos, divididos em um subgrupo de músicos mais o subgrupo de dançarinos. O subgrupo de dançarinos será constituído de quatro subsubgrupos. Em cada subsubgrupo há dois organismos de sexo diferente.

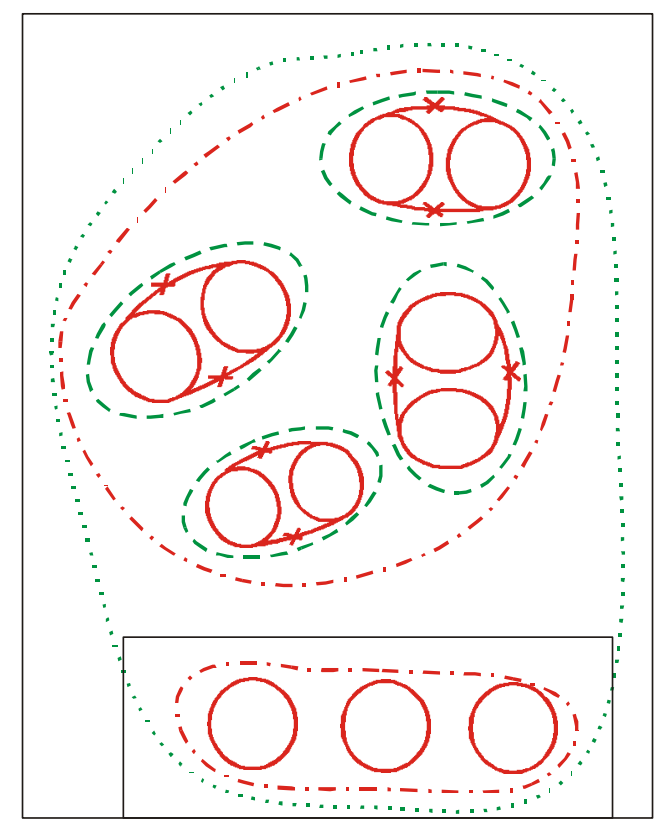

Teoria geral de sistemas

Grupo: Pessoas na sala

Subgrupo: Dançarinos

Músicos

Subgrupo: Pares

Organismo: Seres humanos

Figura 7. Salão de baile
Teoria da Gestalt.

Gestalt fraca

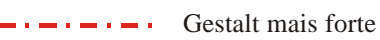

Gestalt mais mais forte

Gestalt mais mais mais forte 
De outro lado, enquanto Gestalt, começamos com a Gestalt fraca de onze pessoas. Esta Gestalt será formada pela parte de músicos e pela parte de dançarinos. Essas partes podem, por sua vez, ser constituídas por Gestalten um pouco mais fortes. A Gestalt dos oito dançarinos apresenta, por sua vez, quatro partes. Cada parte pode ser vista como uma Gestalt mais forte ainda e constituída por duas partes, uma dama e um cavalheiro. Evidentemente, cada parte pode ser vista como uma Gestalt bem forte, se a força dessas Gestalten serão comparadas com a Gestalt do conjunto de pessoas (Volp, 2001.)

\section{O Renascimento das Pesquisas Gestálticas}

Desde mais ou menos 1985, houve um renascimento da psicologia da Gestalt em países de língua inglesa. Trechos dos três autores clássicos voltam a ser "descobertos" e daí vieram a guiar pesquisas atuais. Em 1994, saiu um número da Philosophical Psychology dedicado à Gestalt. É importante que os artigos não se resumem à psicologia da Gestalt, mas incluem a visão de Köhler de um Universo gestáltico (Leeuwen, 1994.)

Spillmann (1997) batiza de abordagem neo-gestáltica o renascimento da psicologia da Gestalt. Vários problemas que no início se apresentavam como pouco claros, hoje em dia, com a tecnologia dos computadores, voltam a ser estudados. E os resultados confirmam os antigos pesquisadores da Gestalt.

Por exemplo, Kóvacs (1996) reviu observações recentes realizadas por psicofísicos, anatomistas e neurofisiólogos que acham muito importantes as idéias antigas quanto à noção de forma e quanto à lei da pregnância. Essa importância refere-se a níveis inferiores ao do organismo. Singer (1995) descobriu que as descargas dos neurônios são sincronizadas de maneira a obedecerem aos critérios gestálticos no agrupamento perceptivo. Essas descargas de milhares de células ocorrem ao mesmo tempo numa escala de milissegundos.

Cataliotti e Gilchrist (1995) reviram, mais uma vez, o efeito Gelb descrito por Koffka (1935/1975). Nesse efeito, um disco preto numa sala preta parece branco. No momento em que um pedaço de papel branco é colocado em frente ao disco, este último muda a aparência para preto. De acordo com muitos pesquisadores, a mudança de luminosidade seria o efeito de um processo local que se estabelece devido à inibição realizada pelas unidades neurais. Cataliotti e Gilchrist demonstraram, após uma série de experimentos, que a explicação gestáltica seria a melhor: o objeto mais iluminado seria visto como branco de acordo com Koffka. Wehner e Stadler (1994) mostram que freqüentes erros em processos não são consequiência de fatos aleatórios, mas de um processo interno gestáltico. A solução é um erro, mas o erro surge da organização. Seja a seguinte adivinhação: "Há dois gansos que passam por baixo de uma ponte. Dois gansos nadam na frente de dois gansos. Dois gansos nadam atrás de dois gansos. Dois gansos estão no meio. Qual é o número mínimo de gansos?” A maioria responde que o número de gansos seria seis, porém o correto é quatro. Se se pensar que os gansos podem nadar um atrás do outro, é fácil imaginar a resposta correta. $\mathrm{O}$ agrupamento em pares devido à pergunta leva à solução errada; entretanto, seria um erro bom, da mesma maneira como outros erros bons são devidos à interferência entre diferentes leis gestálticas, a duas organizações figural e semântica, etc. O erro bom é o caminho para a solução correta.

Baseado na tradição microgenética de Sander e de Werner, Navon $(1971,1981)$ publicou uma série de pesquisas nas quais os sujeitos preferiam, como visão inicial, as características globais, que ocupam um tamanho maior, do que as locais. Podemos citar, como exemplo, o título do artigo do próprio Navon.: um indivíduo vê em primeiro lugar uma floresta, e somente se houver interesse as árvores dessa floresta. Muitos pesquisadores acham que estava de volta o problema da Gestalt. Kimchi (1992), entretanto, supõe que lidar-se com essa questão não tem nada a ver com a suposição Gestalt-parte. A primeira suposição representa dois "níveis" perceptivos, um global e um local. O global seria mais freqüente do que o local. Mas há casos em que a atitude local seria a prevalecente. Esta não era a atitude dos descobridores da microgenética, Sander (1930) e mais tarde Werner (1956)

Köhler publicou dados sobre os acompanhantes elétri$\cos$ diretos no cérebro da visão e da audição. Na época não recebeu reações favoráveis. Entretanto, nos últimos dez ou quinze anos houve uma reviravolta. Em 1992, propuseram os fisiologistas Agnati, Bjelke e Fuxe uma nova teoria para explicar a comunicação no cérebro além da sináptica: a transmissão de volume. O meio de comunicação é o espaço constituído fora dos neurônios. As substâncias químicas dentro dos neurônios se lançam neste espaço extracelular. É uma transmissão lenta, captável externamente. Cerca de $20 \%$ do peso do cérebro é fornecido por esse espaço. Agnati, Bjelke e Fuxe citam diversos pesquisadores que prepararam a sua teoria, começando com Golgi. Entretanto, esqueceram o psicólogo Köhler, que já havia realizado um modelo muito semelhante ao seu. A explicação dos pós-efeitos da figura - a pessoa que observa firmemente uma figura de 5 a 10 minutos verá a área correspondente a essa figura saciada e propaga, para fora dessa área, uma segunda figura - é um deslocamento no campo extra-celular. A explicação é a mesma de Agnati, porém foi publicada muito tempo antes, em 1944. O leitor pode rever o primeiro parágrafo da parte "O isomorfismo psiconeural" (Agnati, Bjelke \& Fuxe, 1992; Köhler \& Wallach, 1944.)

Scheerer (1994) demonstra que não apenas houve uma volta hodierna da teoria da Gestalt, mas que o isomorfismo psiconeural, após sua queda injustificada, voltou como uma das melhores explicações da ocorrência cérebro-consciência. Entretanto, Scheerer acha que Köhler seria correto apenas no caso da percepção. No caso do pensamento, as regras seriam outras.

Westheimer (1999) demonstra que a volta da psicologia gestáltica continua. O impacto da obra inicial de Max Wertheimer em 1910 é importante hoje em dia. Os pesquisadores atuais não aceitam mais a visão simplificada segun- 
do a qual as operações corticais seriam comportamentalizadas. A idéia antiga do isomorfismo psiconeural, ainda que se sirva de modelos mais sofisticados, continua viva.

\section{Trabalhos Brasileiros na Linha Gestáltica}

Falei em pesquisas escritas na língua inglesa, já que os Estados Unidos representam atualmente o principal alicerce da psicologia mundial. Entretanto, grupos menores de psicólogos alemães, italianos e japoneses continuavam as suas publicações baseadas em pesquisadores gestálticos, inclusive no interregno norte-americano.

Entre nós temos ainda poucos textos gestálticos. Vou citar aqueles que recordo. Entretanto, isso não me torna um historiador da psicologia. Não tenho esquema de busca.

Nilton Campos, médico mas professor de psicologia no Rio de Janeiro, caracterizou-se por possuir uma visão gestáltica da ciência. Esteve em contato com Köhler em Berlim, durante uma viagem na Alemanha em 1927, e recebeu Köhler quando de sua rápida vinda em São Paulo na segunda quinzena de agosto de 1930. Na bibliografia de Campos existem pelo menos vinte artigos nitidamente gestaltistas publicados no Rio de Janeiro, principalmente em boletins da Universidade do Brasil. Além disso, realizou o seu trabalho "O método fenomenológico na psicologia" em 1945, que apresentou para concorrer à cátedra de psicologia na Faculdade Nacional de Filosofia e que ganhou. Em 1948, apresentou um resumo no $12^{\circ}$ Congresso Internacional de Psicologia (Campos, 1948; Engelmann, 1978c; Penna, 1987.)

Annita Cabral, aluna de Koffka e de Wertheimer nos Estados Unidos, propagou a visão gestáltica em São Paulo. Em 1944 saíu um artigo seu sobre a obra social de Wertheimer (Cabral, 1944). Em 1946, a Faculdade de Filosofia publicou seu trabalho sobre memória de formas (Cabral, 1946). Recentemente, Ramozzi-Chiarottino (2001) retratou a figura de Cabral. Carolina Martuscelli Bori, assistente na época de Cabral, após passar um período nos Estados Unidos com Tamara Dembo, discípula de Kurt Lewin, publicou uma pesquisa gestáltica sobre interrupção de formas (Martuscelli, 1959). Outro assistente de Cabral, Dante Moreira Leite foi aluno de Heider. Desse contato nasceu em seus cursos de relações pessoais influência da psicologia ingênua de origem heideriana. Deu grande importância à psicologia da literatura. A sua análise do processo criador literário apresenta como base a psicologia da Gestalt (Leite, 1965.)

Walter Hugo de Andrade Cunha é o iniciador do núcleo de ensino e pesquisa da etologia no Brasil. Entretanto, sua teoria básica era gestaltista e tolmaniana. Tolman, apesar de behaviorista, era também em boa parte gestaltista. Cunha publicou em 1963 um texto em que aborda a psicologia tal qual era transmitida por representantes gestaltistas na época (Cunha, 1963). O livro de Cunha, "Explorações no mundo psicológico da formiga", retrata as suas principais descobertas na época. Entretanto, ficou algum tempo numa editora, quando tentou reescrevê-lo segundo a abordagem do behaviorismo operante. Após sua passagem rápida pelo behaviorismo de Skinner, Cunha redescobriu que a primeira versão de sua obra, na qual havia conceitos importantes como propósito e expectativa cognitiva, eram básicos para descrever o comportamento da formiga Nylanderia fulva (Cunha, 1980). Acredita que há duas formas de comportamento: a estrutural, produto da espécie e estudado pelos etólogos, e a funcional, que estuda a mente individual, como era apresentado na primeira versão do livro (Cunha, 1995.)

Ainda que eu tenha tido sempre uma concepção gestáltica desde as aulas com Annita Cabral, as publicações são poucas. No livro "Os estados subjetivos", a concepção do título, estado subjetivo, é gestaltista, provinda do conceito de Ego de Koffka. Num manuscrito recente sobre "Da conceituação de estado subjetivo até a proposição dos escalões de percepto", a teoria é de base gestaltista (Engelmann, 1978a, no prelo; 2001b). Um contínuo para explicar melhor a teoria da força da Gestalt, que publico pela primeira vez no presente artigo, é também uma colaboração minha. Além disso sou organizador e autor da introdução num livro sobre Köhler (Engelmann, 1978b; 1978c.)

Há pouco tempo, Penna (1999) publicou um pequeno livro sobre "Introdução ao gestaltismo".

\section{Meu Ceticismo Mitigado e o Realismo dos Primeiros Gestaltistas}

Não há dúvida que Descartes e muitos outros, contemporâneos e sucessores seus nos séculos XVII, XVIII e XIX, colocaram como essencial para o progresso das ciências naturais a divisão dos processos complexos em processos mais simples. Além disso, para Descartes, os organismos animais e também o organismo humano iam ser melhor conhecidos comparando-os com máquinas. Essa tese de Descartes provocou a repulsa de Köhler. Para Köhler a teoria da máquina está errada para explicação dos animais, e nesse ponto concordo plenamente com a crítica gestáltica (Descartes, 1662/ 1988; Engelmann, 1964; Gilson, 1947; Köhler, 1929/1947.)

De outro lado, Descartes foi o primeiro pensador a colocar a sua própria consciência, pelo menos na parte inicial de suas "Meditações", como o primórdio de qualquer observação, inclusive de observações científicas. Foi sob influência de Descartes, que Hume também pôs sua consciência como o primórdio de suas observações. Para Hume, essa consciência momentânea e individual é a única coisa na qual podemos acreditar piamente. $\mathrm{O}$ universo pode ser observado e nele há coisas que, com o tempo, serão mais acreditáveis ou menos acreditáveis. Nunca todavia essas coisas serão acreditáveis cem por cento. O universo é cético, porém além disso mitigado ou probabilista (Descartes, 1641-1642/1647/ 1967; Engelmann, 1997, 2001a; Hume, 1748/1955.)

Cada indivíduo apresenta a consciência que chamo de imediata num tempo minúsculo, num momento que no ser humano dura de 2 a 4 segundos. De outro lado o indivíduo pode perceber Gestalten temporais que duram, na maioria das vezes, bem mais do que 4 segundos. Como explicar esse acontecimento? Köhler (1920/1938a) escreveu que os momentos são passagens de uma topografia total. Esses momentos não são, de maneira nenhuma, as partes da Gestalt. 
Acredito que apesar da consciência-imediata ${ }^{21}$ durar um momento não limitado, durante este momento - ou os momentos em que se fica consciente - a consciência-imediata capta os momentos anteriores na percepção da Gestalt temporal (Engelmann, 2001a.)

Wertheimer, Koffka e Köhler foram realistas. Eu, no entanto, sou cético probabilista. Por razões provavelmente evolucionárias, os seres humanos apresentam uma consciência individual e momentânea através da qual são capazes de construir um universo (Engelmann, 2001a.) Esse universo me parece muito melhor captado na linha gestáltica do que na linha elementarista.

\section{Conclusão}

Acho que possuo a melhor justificação da certeza de se observar o todo, a Gestalt, e não os elementos. Em 1952 estava estudando física médica na Faculdade de Medicina. Num livro da época, constava a afirmação de que os átomos dos seres vivos estão em constante mudança. Em mais ou menos dois anos, os átomos de cachorros, de gatos, de seres humanos são quase totalmente diferentes. Uma pessoa que vi há cinco anos e que vejo hoje em dia não apresenta quase nenhuma parte igual, pelo menos com relação à sua formação básica: os átomos. Em 2000, quis ter afirmação contemporânea desse fato. Falei com meu colega Menna-Barreto que, por sua vez, entrou em contato com um bioquímico, Chuck Farah. Farah confirmou-me que as "moléculas "biológicas' ... estão sempre se transformando in vivo"22 (Alberts \& cols., 1994.)

Para mim, concordando com a teoria geral da Gestalt e não apenas com a originária escola psicológica - e concordando com a teoria geral dos sistemas, os seres humanos estão sempre se transformando. Entretanto, são no entanto sempre os mesmos. O importante é a Gestalt total do organismo e não as suas partes constituintes. Quando se observam moléculas, são moléculas como um todo e não suas partes atômicas. Quando se observam órgãos do corpo, são os órgãos como um todo e não seus átomos constituintes. E quando se observam pessoas, são pessoas como um todo e não os seus incontáveis números de átomos. São as pessoas que permanecem através do tempo.

Ao contrário de grande parte das teorias que julgam serem os elementos que se juntam na constituição de coisas ou organismos, os gestaltistas invertem a questão. No Universo, o importante são os todos ou Gestalten. Esses todos podem constituir as suas próprias partes.

21 Na minha teoria há duas consciências: a consciência-imediata, que o indivíduo humano observa imediatamente e por um período não maior do que alguns segundos, e a consciência-mediata, que é parte dos organismos de seres humanos ou não-humanos. Essa consciênciamediata é observada através da mediação da memória - consciência-mediata-do-observador — ou através de diversas mediações na percepção de outros organismos — consciência-mediata-de-outros (Engelmann, 1997, 1998, 2001a.)

22 Resposta de Chuck Farah à minha pergunta num e-mail recebido em 11-4-2000.
Depois de tudo que disse e depois do que afirmei na parte de psicólogos brasileiros, sou gestaltista? Dizia o próprio Wolfgang Köhler em reuniões com seus alunos:

"A única coisa da qual tenho medo, é que vocês queiram se tornar verdadeiros psicólogos da Gestalt. Eu, propriamente dito, não o sou." ${ }^{23}$

Para ser gestaltista, sistematista, behaviorista ou cognitivista espera-se que o pesquisador carregue um rótulo para classificá-lo. Entretanto, esses quatro nomes não são tão nítidos e apresentam, cada um, uma série de significados. Sou gestaltista por abordar sempre em primeiro lugar o todo e, a seguir, as partes deste todo. Sou sistematista por acreditar, com a evolução dos seres vivos e dos seres minerais, há uma série de sistemas, cada um se superpondo aos outros com exceção do mais inferior de todos. Sou behaviorista por abordar o organismo, humano ou não-humano, sempre fora de mim, de minha consciência-imediata. E sou cognitivista pela seleção de assuntos que quero estudar. Entretanto sou, em primeiro lugar, um cientista empírico.

\section{Referências}

Agnati, L.F.; Bjelke, B. e Fuxe, K. (1992) Volume transmission in the brain. American Scientist, 80, 362-373.

Alberts, B., Bray, D., Lewis, J., Raff, M.; Roberts, K. e Watson, J. D. (Orgs.) (1994) Molecular of the cell. 3a. ed. New York: Garland.

Anjos, M. dos e Ferreira, M.B. (Orgs.) (1999) Aurélio Século XXI. Rio de Janeiro: Ed. Nova Fronteira.

Aristóteles (1953) La métaphysique. (J. Tricot, Trad.). Paris: J. Vrin. Aristóteles (1956) Les parties des animaux. (P. Louis, Trad.). Paris: "Les belles lettres".

Aristóteles (1962) La politique (J. Tricot, Trad.). Paris: J. Vrin.

Arnheim, R. (1986) The two faces of gestalt psychology. American Psychologist, 41, 820-824.

Ash, M.G. (1995) Gestalt psychology in German culture, 18901967. Cambridge, UK: Cambridge University Press.

Bertalanffy, L. von (1933) Modern theories of development. An introduction to theoretical biology (J.H. Woodger, Trad.). Oxford, UK: Oxford University Press.

Bertalanffy, L. von (1975) The history and development of general system theory. Em E. Taschdjian (Org.), Perspectives on general system theory by Ludwig von Bertalanffy (pp. 149-169). New York: George Braziller.

Bertalanffy, L. von (1977) Teoria geral dos sistemas (F.M. Guimarães, Trad.) Petrópolis: Vozes.

Boring, E.G. (1950) A history of experimental psychology. New York: Appleton-Centuy-Crofts. (Trabalho original publicado em 1929)

Bringmann, W.G., Bringmann, N.J. e Ungerer, G.A. (1980) The establishment of Wundt's laboratory: An archival and docu-

23 Tradução minha, feita para a "Introdução" do livro sobre a obra de Köhler (Engelmann, 1978c), de trecho citado em alemão por Teuber (1967.) 
mentary study. Em W.G. Bringmann e R.D. Tweney (Org.), Wundt studies. A centennial collection (pp. 123-157). Toronto: C. J. Hogrefe.

Bunge, M. (1977) General systems theory. General Systems, 22, $87-90$.

Cabral, A.C.M. (1944) Max Wertheimer e as ciências sociais. Sociologia, 6 (2), 111-122.

Cabral, A.C.M. (1946) O conflito dos resultados dos experimentos sobre a memória de formas. Boletim $n^{\circ} 76$ da FFCL da USP. Psicologia $n^{\circ} 2$.

Campos, N. (1948) Fundamentals of the phenomenological attitude in modern psychology. Universidade do Brasil. Instituto de Psicologia. Monografias Psicológicas, $\mathrm{n}^{\circ} 1$.

Cataliotti, J. \& Gilchrist, A. (1995) Local and global processes in surface lightness perception. Perception and Psychophysics, 57, 125-135.

Cunha, W.H.A. (1963) Os fatos da psicologia. Boletim $n^{\circ} 281 \mathrm{da}$ FFCL da USP. Psicologia $\mathrm{n}^{\circ} 11$.

Cunha, W.H.A. (1980) Explorações no mundo da formiga. São Paulo: Ática.

Cunha, W.H.A. (1995) Trilha de formiga, senda de psicólogo e etólogo (meus caminhos e descaminhos no estudo do comportamento). Psicologia USP, 6 (1), 43-73.

Descartes, R. (1967) Les méditations, les objections et les réponses. Em F. Alquié (Org.), Descartes Euvres philosophiques. Tome II (1638-1642) (pp. 375-890). Paris: Garnier. (Trabalho original publicado em 1647; texto em latim de 1641-1642)

Descartes, R. (1988) L'homme. Em F. Alquié (Org.), Descartes Euvres philosophiques. Tome I (1618-1637) (pp. 379-480). Paris: Garnier. (Trabalho original publicado em 1662)

Engelmann, A. (1964) Descartes e a psicologia científica. Jornal Brasileiro de Psicologia, 1 (2), 13-35.

Engelmann, A. (1978a) Os estados subjetivos: Uma tentativa de classificação de seus relatos verbais São Paulo: Ática.

Engelmann, A. (Org.) (1978b) Wolfgang Köhler. São Paulo: Ática.

Engelmann, A. (1978c) Introdução. Em A. Engelmann (Org.), Wolfgang Köhler (pp. 7-36). São Paulo: Ática.

Engelmann, A. (1997) Dois tipos de consciência: a busca da autenticidade. Psicologia USP, 8 (2), 25-67.

Engelmann, A. (1998) Ciência natural e consciência. Psicologia: Reflexão e Crítica, 11, 273-280.

Engelmann, A. (2001a) O meu-mundo e o resto-do-mundo. Psicologia: Reflexão e Crítica, 14, 211-223.

Engelmann, A. (1978a, no prelo) Da conceituação de estado subjetivo até a proposição dos escalões de percepto. Psicologia: Reflexão e Crítica.

Flavell, J. H. \& Draguns, J. (1957) A microgenetic approach to perception and thought. Psychological Bulletin, 57, 197-217.

Forgus, R.H. (1971) Percepção (N. P. Mejías, Trad.). São Paulo: Herder, Editora da Universidade de Brasília, Editora da Universidade de São Paulo.

Gilson, É. (1947) Commentaire historique. Em É. Gilson (Org.), René Descartes - Discours de la méthode (pp. 79-477). Paris: J. Vrin.

Goerdt, W. (1974) Holismus. Em J. Ritter (Org.), Historisches Wörterbuch der Philosophie. Band 3 (pp. 1167-1168). Darmstadt, Alemanha Ocidental: Wissenschaftliche Buchgesellschaft.
Goudge, T. A. (1967) Emergent evolutionism. Em P. Edwards (Org.), The encyclopaedia of philosophy (pp. 474-477). New York: Macmillan e Free Press.

Grande enciclopédia Larousse cultural (Org.) (1998) Cidade: Nova Cultura.

Heider, F. (1970) Gestalt theory: Early history and reminiscences. Journal of the History of the Behavioral Sciences, 6, 131-139.

Henle, M. (1984) Isomorphism: Setting the record straight. Psychological Research, 46, 317-327.

Herrmann, T. (1974a) Ganzheit. I. Em J. Ritter (Org.), Historisches Wörterbuch der Philosophie. Band 3 (p. 20). Darmstadt, Alemanha Ocidental: Wissenschafliche Buchgesellschaft.

Herrmann, T. (1974b) Ganzheitspsychologie. Em J. Ritter (Org.), Historisches Wörterbuch der Philosophie. Band 3 (pp.22-23) Darmstadt, Alemanha Ocidental: Wissenschaftliche Buchgesellschaft.

Houaiss, A., Villar, F.M. e Franco, M. (Orgs.) (2001) Dicionário Houaiss da língua portuguesa. Rio de Janeiro: Objetiva.

Hull, C. L. (1951) Essentials of behavior. New Haven, CT: Yale University Press.

Hume, D. (1955) An inquiry concerning human understanding. Indianapolis, IN: Liberal Arts Press. (Trabalho original publicado em 1748)

Jantsch, E. (1980) The self-organizing universe. Oxford, UK: Pergamon.

Kimchi, R. (1992) Primacy of wholistic processing and global/local paradigm: A critical review. Psychological Bulletin, 112, 24-38.

Koffka, K. (1924) Introspection and the method of psychology. British Journal of Psychology, 15, 149-161.

Koffka, K. (1938) Reply to V. Benussi. Em W. D. Ellis (Condensador e tradutor), A source book of Gestalt psychology (pp. 371-378). London: Routledge \& Kegan Paul. (Trabalho original publicado em alemão em 1915).

Koffka, K. (1975) Princípios da psicologia da Gestalt (A. Cabral, trad.). São Paulo: Editora Cultrix, Editora da Universidade de São Paulo. (Trabalho original publicado em inglês, em 1935)

Köhler, W. (1927) The mentality of apes (E. Winter, Trad. do alemão). London: Routledge \& Kegan Paul. (Trabalho original publicado em alemão, em 1917)

Köhler, W. (1938a) Physical Gestalten. Em W. D. Ellis (Condensador e tradutor), A source book of Gestalt psychology (pp. 17-54). London: Routledge \& Kegan Paul. (Trabalho original publicado em alemão em 1920)

Köhler, W. (1938b) The place of value in a world of facts. New York: Liveright.

Köhler, W. (1944) Max Wertheimer 1880-1945. Psychological Review, 51, 143-146.

Köhler, W. (1947) Gestalt psychology. New York: Liveright. (Texto original publicado em 1929)

Köhler, W. (1969) The task of Gestalt psychology. Princeton, NJ: Princeton University Press.

Köhler, W. (1971a) On unnoticed sensations and errors of judgment. Em M. Henle (Org.), The selected papers of Wolfgang Köhler (pp. 13-39). New York: Liveright. (Texto original publicado em alemão, em 1913)

Köhler, W. (1971b) Psychology and natural science. Em M. Henle 
(Org.), The selected papers of Wolfgang Köhler (pp. 252-273). New York: Liveright. (Texto original publicado em alemão, em 1957)

Köhler, W. (1971c) On the problem of regulation. Em M. Henle (Org.), The selected papers of Wolfgang Köhler (pp. 305-326). New York: Liveright. (Texto original publicado em alemão, em 1927)

Köhler, W. (1978) O problema mente-corpo. Em A. Engelmann (Org.), Wolfgang Köhler (pp. 129-147) (J. S. de C. Pereira e V. L. Bianco, Trads.) São Paulo: Ática. (Trabalho original publicado em inglês, em 1960)

Köhler, W. \& Wallach, H. (1944) Figural after-effects. An investigation of visual processes. Proceedings of the American Philosophical Society, 88, 269-357.

Kovács, I. (1996) Gestalten of today: early processing of visual contours and surfaces. Behavioural Brain Research, 82, 1-11.

Lewin, K. (1936) Principles of topological psychology (F. Heider e G. M. Heider, trads.). New York: McGraw-Hill.

Leeuwen, Cees van (Org.) (1994) Special issue on Gestalt. Philosophical Psychology, 7, $\mathrm{n}^{\circ} 2$.

Leite, D. M. (1965) Psicologia e literatura. Conselho Estadual da Cultura.

Martuscelli, C. (1959) Os experimentos de interrupção de tarefa e a teoria de motivação de Kurt Lewin. Boletim $n^{\circ} 174$ da FFCL da USP. Psicologia $\mathrm{n}^{\circ} 5$.

Metzger, W. (1974a) Gestalt. II. Em J. Ritter (Org.), Historisches Wörterbuch der Philosophie. Band 3 (pp. 547-548). Darmstadt, Alemanha Ocidental: Wissenschafliche Buchgesellschaft.

Metzger, W. (1974b) Gestaltpsychologie. Em J. Ritter (Org.), Historisches Wörterbuch der Philosophie. Band 3 (pp. 549550). Darmstadt, Alemanha Ocidental: Wissenschaftliche Buchgesellschaft.

Metzger, W. (1974c) Gestaltqualität. Em J. Ritter (Org.), Historisches Wörterbuch der Philosophie Band 3 (pp. 550-551). Darmstadt, Alemanha Ocidental: Wissenschaftliche Buchgesellschaft.

Miller, J. G. (1978) Living systems. New York: McGraw-Hill.

Navon, D. (1977) Forest before trees: The precedence of global features in visual perception. Cognitive Psychology, 9, 353383.

Navon, D. (1981) The forest revisited: More on global precedence. Psychological Research, 43, 1-32.

Needham, J. (1942) Biochemistry and morphogenesis. Cambridge, UK: University Press.

Osgood, C. E. (1953) Method and theory in experimental psychology. New York: Oxford University Press.

Penna, A. G. (1987) Nilton Campos e a divulgação do método fenomenológico e do gestaltismo. História da psicologia: apontamentos sobre as fontes e sobre algumas das figuras mais expressivas da psicologia na Cidade do Rio de Janeiro, IV (pp. 16-28). Rio de Janeiro: ISOP, Texto do centro de pós-graduação em psicologia, $n^{\circ} 7$.

Penna, A.G. (1999) Introdução ao gestaltismo. Rio de Janeiro: Imago.

Ramozzi-Chiarottino, Z. (2001) Annita Castilho Cabral. Rio de Janeiro: Imago.

Ross, W.D . (1949) Aristotle. London: Methuen. (Trabalho original publicado em 1923)
Sander, F. (1930) Structure, totality of experience, and Gestalt. Em C. Murchison (Org.), Psychologies of 1930 (pp. 188-204) Cidade: Editora.

Sander, F. (1967) Experimentelle Ergebnisse der Gestaltpsychologie. Em F. Sander e H. Volkelt (Orgs.), Ganzheitspsychologie (pp. 73-112). Munique, Alemanha Ocidental: C. H. Beck'sche Verlagsbuchhandlung. (Trabalho originalmente publicado em 1928)

Scheerer, E. (1994) Psychoneural isomorphism: historical background and current relevance. Philosophical Psychology, 7, 183210.

Sekuler, R. (1996) Motion perception: A modern view of Wertheimer's 1912 monograph. Perception, 25, 1243-1258.

Singer, W. (1995) Time as coding space in neocortical processing: A hypothesis. Em M. S. Gazzaniga (Org.), The cognitive neurosciences. Cambridge, MA: MIT.

Skinner, B.F. (1953) Science and human behavior. New York: Macmillan.

Spillmann, L. (1997) Colour in a larger perspective: the rebirth of Gestalt psychology. Perception, 26, 1341-1352.

Strube, W. (1974) Gestalt. I. (1974) Em J. Ritter (1974), Historisches Wörterbuch der Philosophie. Band 3 (pp. 540-547). Darmstadt, Alemanha Ocidental: Wissenschafliche Buchgesellschaft.

Teuber, H.-L. (1967) Wolfgang Köhler zum Gedenken. Psychologische Forschung, 31, X-XI.

Tolman, E.C. (1932) Purposive behavior in animals and men. New York: Century

Verstegen, I. (2000) Gestalt psychology in Italy. Journal of the History of the Behavioral Sciences, 36, 31-42.

Volp, C.M. (2001) De dança em dança: dos pés aos instrumentos, do corpo à música, da razão ás emoções. Tese de livre-docência não publicada. UEP, Inst. de Biociências. Rio Claro, SP.

Watson, J.B. (1929) Psychology from the standpoint of a behaviorist. Philadelphia, PA: J.B. Lippincott. (Trabalho original publicado em 1919)

Watson, J.B. (1961) Psychology as the behaviorist views it. Em T. Shipley (Org.), Classics in psychology. New York: Philosophical Library. (Trabalho original publicado em 1913)

Wehner, T. e Stadler, M. (1994) The cognitive organization of human errors: a Gestalt theory perspective. Applied Psychology: An international review, 43, 565-584.

Weiszflog, W. (Org.) (1998) Michaelis. Moderno dicionário da língua portuguesa. São Paulo: Comp. Melhoramentos. (Trabalho original publicado em 1962)

Werner, H. (1956) Microgenesis and aphasia. Journal of Abnormal and Social Psychology, 52, 347-353.

Wertheimer, Max (1938a) Gestalt theory. Em W. D. Ellis (Condensador e tradutor), A source book of Gestalt psychology (pp. 1-11). London: Routledge \& Kegan Paul. (Trabalho original publicado em 1924)

Wertheimer, Max (1938b) Laws of organization in perceptual forms. Em W. D. Ellis (Condensador e tradutor), A source book of Gestalt psychology (pp. 71-88). London: Routledge \& Kegan Paul. (Trabalho original publicado em 1923)

Wertheimer, Max (1945) Productive thinking. New York: Harper.

Wertheimer, Max (1961) Experimental studies on the seeing of motion. Em T. Shipley (Org.), Classics in psychology (pp. 1032- 
1089). New York: Philosophical Library. (Trabalho original publicado em 1912)

Wertheimer, Michael (1979) A brief history of psychology. Cidade: Editora.
Westheimer, G. (1999) Gestalt theory reconfigured: Max Wertheimer's anticipation of recent developments in visual neuroscience. Perception, 28, 5-15.

Wundt, W. (1905) Grundriss der Psychologie. Leipzig: Wilhelm Engelmann (Trabalho original publicado em 1896)

\section{Mudanças nas exigências para a preparação de manuscritos}

Mudanças nas exigências para a preparação de manuscritos podem inicialmente ser inconvenientes e frustrantes para os autores que submetem seus trabalhos. (APA, 1994, p. xxx)

No caso de Psicologia: Teoria e Pesquisa, os padrões adotados são baseados nas Normas da American Psychological Association [APA]. Novas exigências têm sido introduzidas, acompanhando as atualizações do estilo APA (como foi o caso da $4^{a}$ edição do Manual de Publicação, publicado em 1994). Em 1995, também houve mudanças devidas aos procedimentos operacionais e à tecnologia de produção, com a atualização dos procedimentos de editoração eletrônica e o novo formato da revista.

As exigências de formatação visam facilitar as tarefas de exame dos manuscritos e de produção dos artigos. Estabelecem limites convencionais na publicação científica - praticamente não trazem novidades; são apenas explicitações e detalhamentos que orientam os autores no cumprimento de exigências antigas.

As notas de Orientação aos Autores, publicadas regularmente desde o Volume 10, trazem lembretes de exigências típicas da publicação, dando destaque às providências mais comuns no fluxo de tramitação de manuscritos. Tais lembretes referem-se a orientações encontradas em todos os textos de orientação para a publicação científica - p. ex., sobre a qualidade da redação, e a organização do relato.

Para atendimento das normas em vigor, os autores devem basear-se nas instruções publicadas no número mais recente da Revista.

Para obter orientação mais detalhada, os autores devem consultar o Manual de Publicação da APA (1994, $4^{a}$ ed.).

O Editor pode ser consultado, caso persistam dúvidas.

Convidamos os autores interessados a escreverem para $P$ sicologia: Teoria e Pesquisa solicitando informações, apresentando suas críticas e sugestões. 